\title{
Magnitude-frequency distribution of volcanic explosion earthquakes
}

\author{
Takeshi Nishimura ${ }^{1 *}$, Masato Iguchi ${ }^{2}$, Mohammad Hendrasto $^{3}$, Hiroshi Aoyama ${ }^{4}$, Taishi Yamada ${ }^{4}$, \\ Maurizio Ripepe ${ }^{5}$ and Riccardo Genco ${ }^{5}$
}

\begin{abstract}
Magnitude-frequency distributions of volcanic explosion earthquakes that are associated with occurrences of vulcanian and strombolian eruptions, or gas burst activity, are examined at six active volcanoes. The magnitude-frequency distribution at Suwanosejima volcano, Japan, shows a power-law distribution, which implies self-similarity in the system, as is often observed in statistical characteristics of tectonic and volcanic earthquakes. On the other hand, the magnitude-frequency distributions at five other volcanoes, Sakurajima and Tokachi-dake in Japan, Semeru and Lokon in Indonesia, and Stromboli in Italy, are well explained by exponential distributions. The statistical features are considered to reflect source size, as characterized by a volcanic conduit or chamber. Earthquake generation processes associated with vulcanian, strombolian and gas burst events are different from those of eruptions ejecting large amounts of pyroclasts, since the magnitude-frequency distribution of the volcanic explosivity index is generally explained by the power law.
\end{abstract}

Keywords: Magnitude, Exponential distribution, Power law, Explosion

\section{Introduction}

Volcanic explosion earthquakes (hereafter termed EXs) are earthquakes that are observed in vulcanian and strombolian eruptions, or gas bursts, which often accompany strong air shocks or infrasonic signals. A pioneer study by Minakami (1960) first defined EXs, classifying volcanic earthquakes into four types: A-, B-type, explosion earthquake, and tremor. He indicated that EXs at Sakurajima, Japan, follow Ishimoto-Iida's formula of $n(A)=k A^{-m}$, where $n(A)$ represents the number of earthquakes with a maximum amplitude of $A, m$ is the coefficient called Ishimoto-Iida's $m$ value, and $k$ is a proportional coefficient (Ishimoto and Iida 1939). This relationship is linked to the Gutenberg-Richter equation (G-R eq.) that explains the magnitude-frequency distribution of earthquakes in general, and the $m$ value is related to the $b$ value in the $\mathrm{G}-\mathrm{R}$ eq. as $m=b+1$ (Asada et al. 1950; Suzuki 1953). These observed

\footnotetext{
*Correspondence: nishi@zisin.gp.tohoku.ac.jp

1 Department of Geophysics, Graduate School of Science, Tohoku University, 6-3 Aramaki-aza Aoba, Aoba-ku, Sendai 980-8578, Japan Full list of author information is available at the end of the article
}

magnitude-frequency distributions are often termed power laws, which are interpreted to be related to fractal properties and self-similar systems.

Since Minakami's pioneering work in 1960, magnitudefrequency distributions have been investigated at active volcanoes (e.g., Tanaka 1967; Shimozuru et al. 1971; Tanaka et al. 1972; Del Pezzo et al. 1974; Rowe et al. 2000). These previous studies often plotted the number of EXs versus amplitude in double-logarithmic graphs to estimate $m$ values. However, most of the figures presented seem not to be well matched with the Ishimoto-Iida's formula (power law). For example, Tanaka (1967) pointed out a break in the Ishimoto-Iida's formula at large amplitudes for EXs at Sakurajima and interpreted the break as related to crater size. Magnitude-frequency distributions of EXs associated with strombolian eruptions at AkitaKomagatake, Japan, were explained by combinations of two power laws using two $m$ values (Tanaka et al. 1972). Rowe et al. (2000) examined the magnitude-frequency distribution of EXs associated with frequent strombolian explosions within the summit crater lake at Erebus volcano, Antarctica. They showed that the distribution follows an approximate power law with $b$ value of about 
1.7 and pointed out that an inflection in the cumulative distribution curve may be due to low detection level of small events, distinct source populations or a preferred median bubble size. These previous studies indicate that EXs do not follow a simple relation as represented by the Ishimoto-Iida's formula or G-R eq. Such divergence of the magnitude-frequency distribution is also found for volcanic tremors. Benoit and McNutt (2003) analyzed duration times and amplitudes of volcanic tremors and followed exponential rather than power-law scaling.

Although magnitude-frequency distributions provide some of the most basic and important information to understanding explosive eruption processes, investigations of the statistical characteristics of EXs are limited in number. In the present study, therefore, we examine the magnitude-frequency distribution characteristics of EXs at different volcanoes. The EXs we analyze are those associated with vulcanian and strombolian eruption styles and gas bursts at Sakurajima, Suwanosejima, and Tokachi-dake in Japan, Semeru and Lokon in Indonesia, and Stromboli in Italy. Note that Plinian style explosive eruptions are associated with eruption tremors (e.g., McNutt and Nishimura 2008) rather than EXs, and they are not the target of the present study. Since EXs are considered to be caused by rapid conduit pressure changes in volcanic explosions, magnitude-frequency distributions provide us with the basic statistical attributes of eruptions and clues to understanding eruption dynamics. We examine the magnitude-frequency distribution of EXs at the six volcanoes identified above and discuss their relationship to the volcanic systems.

\section{Magnitude-frequency distributions}

\section{Vulcanian eruptions at volcanoes in Japan}

Figure 1a shows the locations of the volcanoes we analyzed in Japan: Sakurajima, Suwanosejima and
Tokachi-dake. The Sakurajima Volcano Research Center (SVRC) of Kyoto University started seismic observation at Sakurajima in 1968. Since then, seismic signals have been recorded with an S-1000 seismometer at Harutayama (HRT) station, which is $2.7 \mathrm{~km}$ from the active crater at Minami-dake. The amplitudes of seismic and acoustic signals for vulcanian explosions have been continuously cataloged; here we analyze the 49-year period from 1963 to 2011. Vulcanian explosions frequently occurred at Minami-dake crater until 2007; however, the volcanic activity reduced after 2000 (Iguchi 2013). Since 2008, Showa crater, which is about $0.5 \mathrm{~km}$ southeast of Minami-dake, has been activated, while there have been few explosions at Minami-dake (Iguchi et al. 2013). In the following analysis, therefore, we separate Sakurajima data into two periods, from 1968 to 1999 and from 2008 to 2011. The former represents the characteristics of explosions at Minami-dake, while the latter represents Showa crater.

Figure 2 shows frequency distributions of the maximum amplitudes of EXs at Minami-dake and Showa crater. For Minami-dake, maximum amplitude of EXs ranges up to $0.3 \mathrm{~mm}$ and the cumulative number of events is 2584, while for Showa crater, maximum amplitude is about $0.1 \mathrm{~mm}$, and the total number of events is 2633 . The double-logarithmic graphs for both craters are convex, indicating that the Ishimoto-Iida's formula may not explain the observed magnitude-frequency distributions. On the other hand, the cumulative number of EXs plotted in semilogarithmic graphs is well fitted by a straight line. This suggests that the EX magnitude-frequency distributions at Sakurajima follow exponential rather than power-law scaling.

We analyze seismic data from Suwanosejima volcano for the period from January to June 2010, during which time about 120 small vulcanian eruptions were
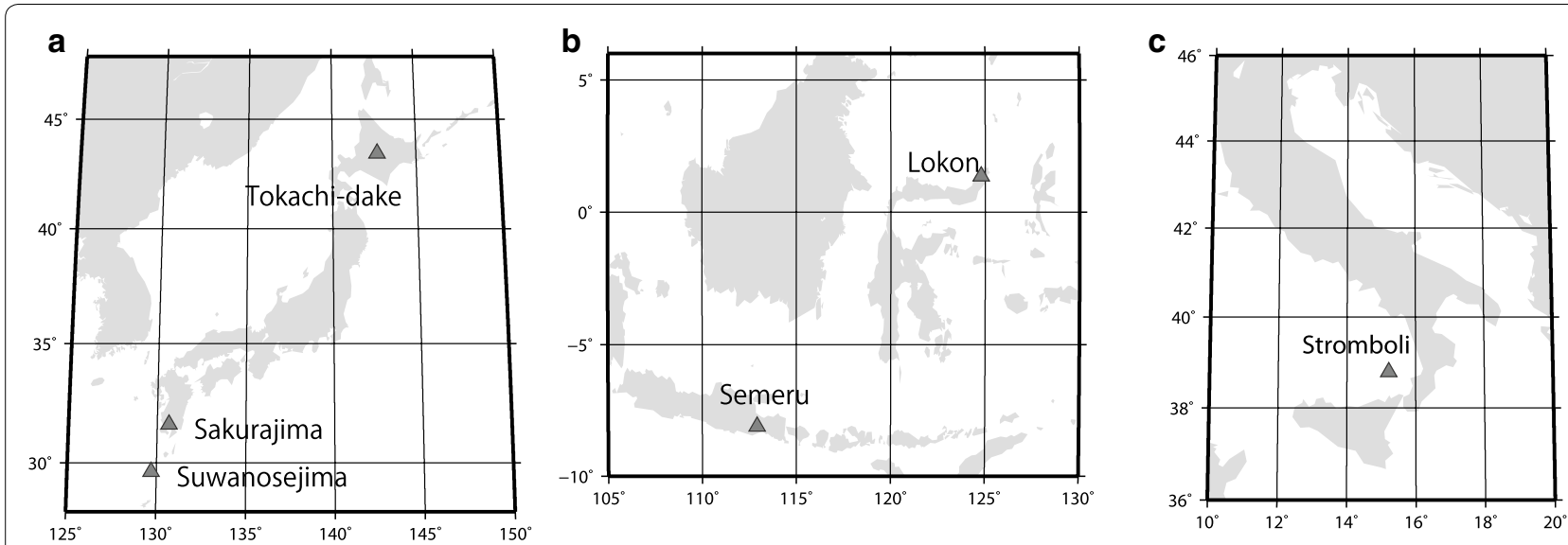

Fig. 1 Locations of volcanoes analyzed. a Japan, b Indonesia, and c Italy 


\section{a Sakurajima 1963-1999}

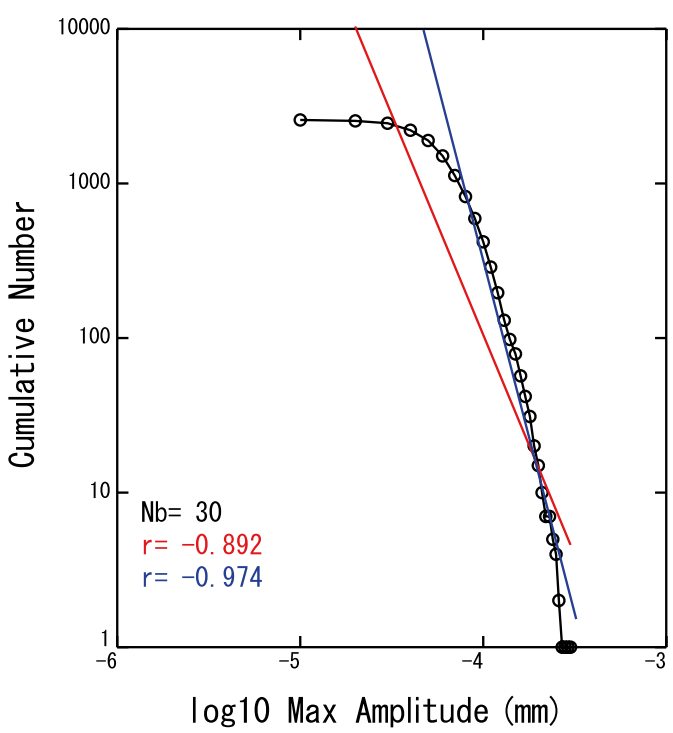

b Sakurajima 2008-2011

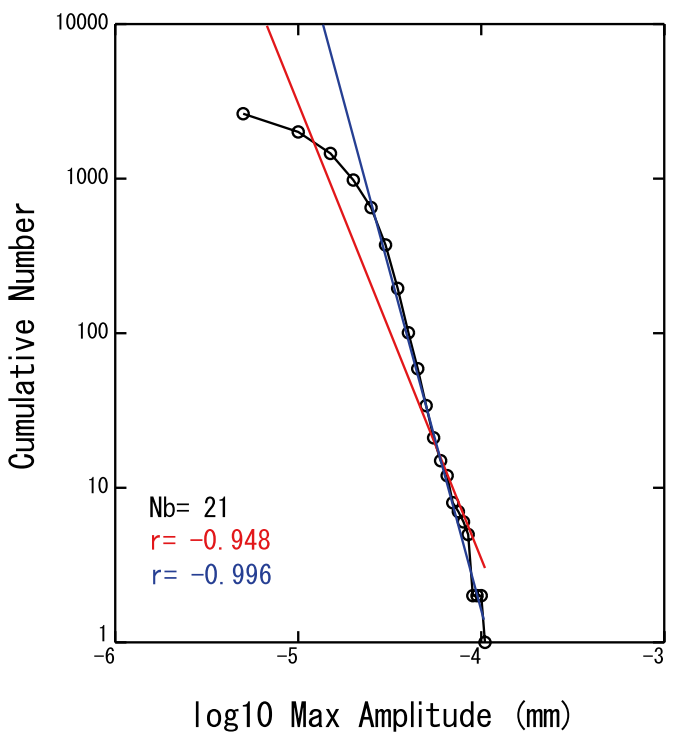

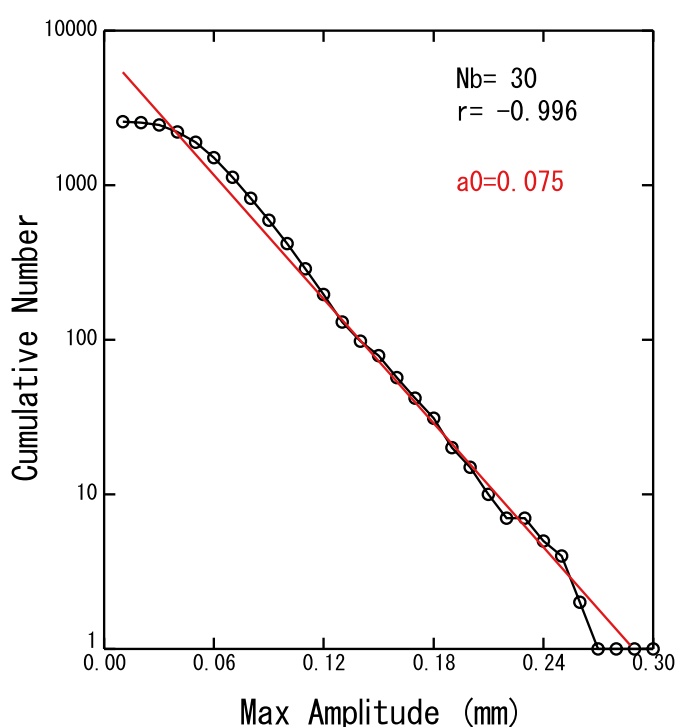

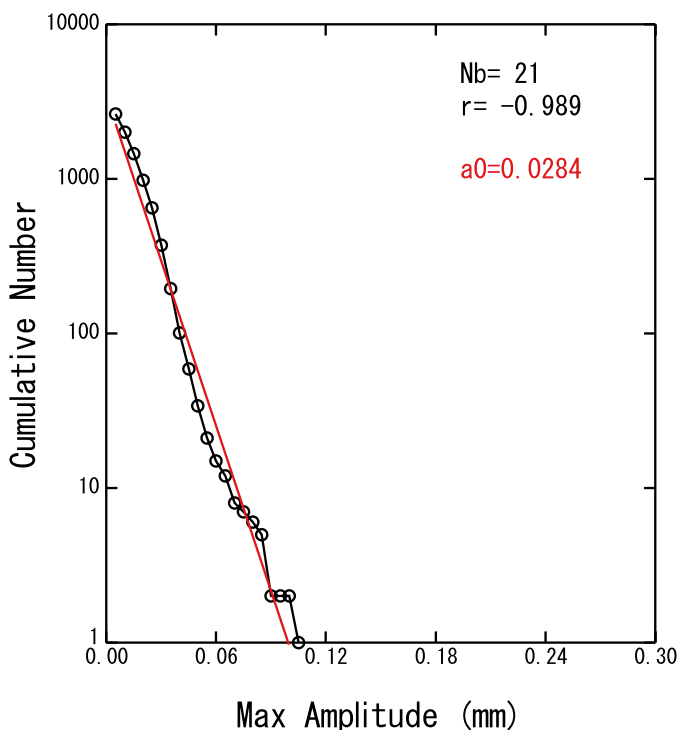

Fig. 2 Magnitude-frequency distributions of explosion earthquakes at Sakurajima volcano, Japan, for a 1963-1999 (Minami-dake crater) and b 2008-2011 (Showa crater). Left-hand graphs have log-log scale, and right-hand ones semilogarithmic. Parameters of $N_{\mathrm{b}}, r$ and $a_{0}$ represent the number of bins, correlation coefficients and characteristic amplitude of the exponential distribution. Regression lines and correlation coefficients are in red. Regression lines and correlation coefficients in blue are determined from data with the five lowest-amplitude bins removed

observed. We examine raw seismograms from a broadband seismometer (STS-2, Streckeisen) located at SWA station, about $500 \mathrm{~m}$ south of the active crater (Iguchi et al. 2008). Volcanic tremors associated with continuous ash emission were often observed during the explosive activity at Suwanosejima, and eruptive activities sometimes ceased for several weeks or more (Nishimura et al. 2013). Hence, we manually pick EXs and extract their maximum amplitudes from the raw broadband seismometer records. Figure 3 plots the cumulative number of EXs versus maximum seismic amplitude in double-logarithmic and semilogarithmic graphs. Contrary to the Sakurajima, the magnitude-frequency distribution plots as linear in the double-logarithmic graph for Suwanosejima, suggesting a power-law relationship in EXs. 


\section{a Suwanosejima}

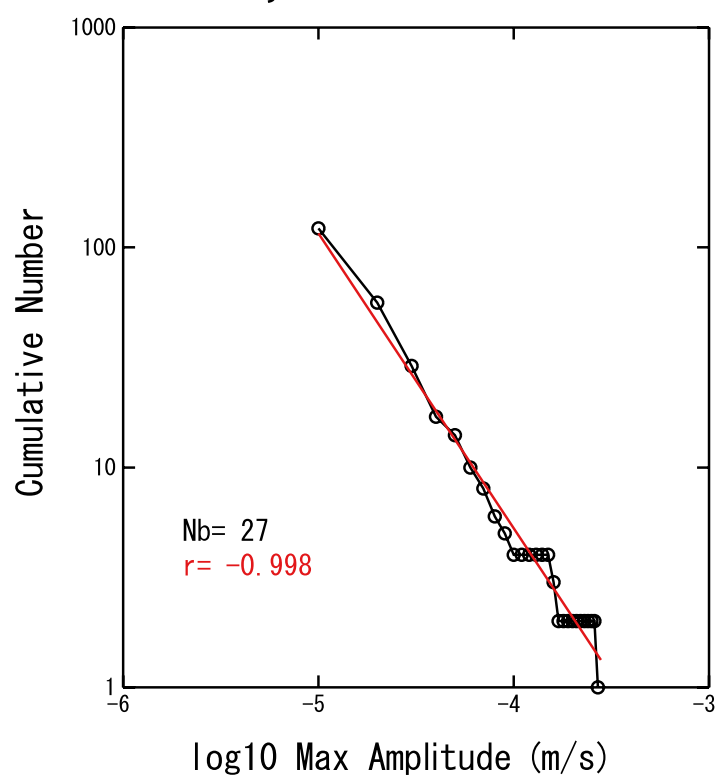

\section{b Tokachi}

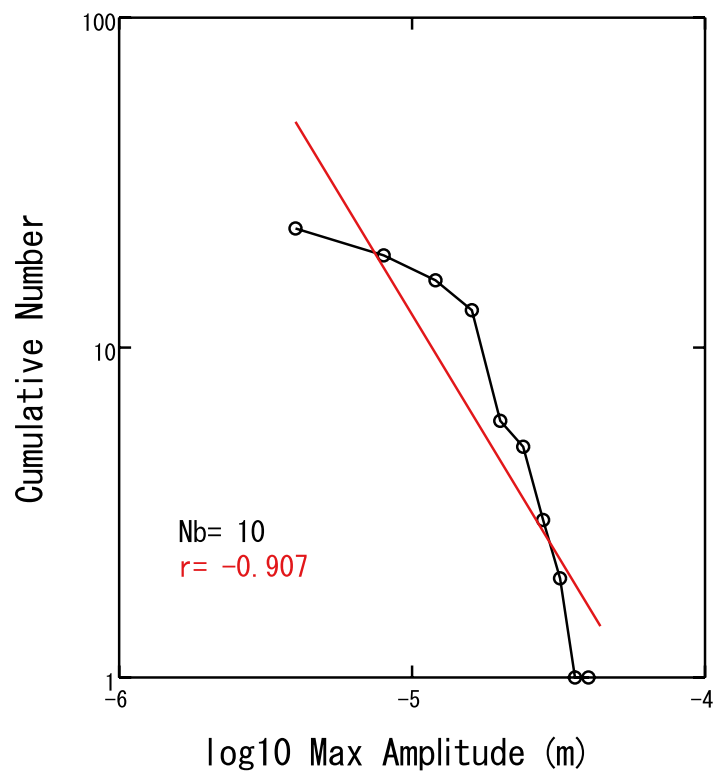

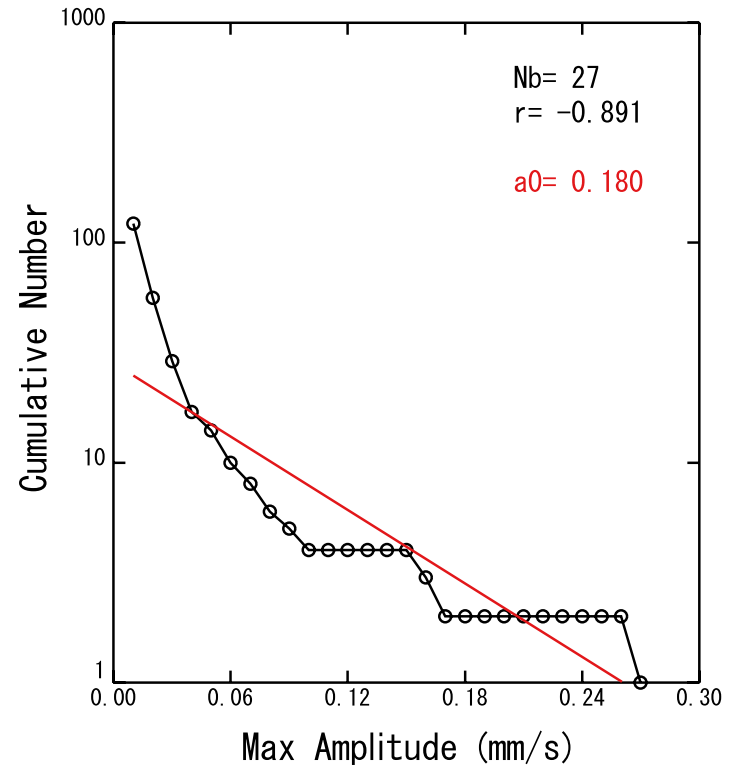

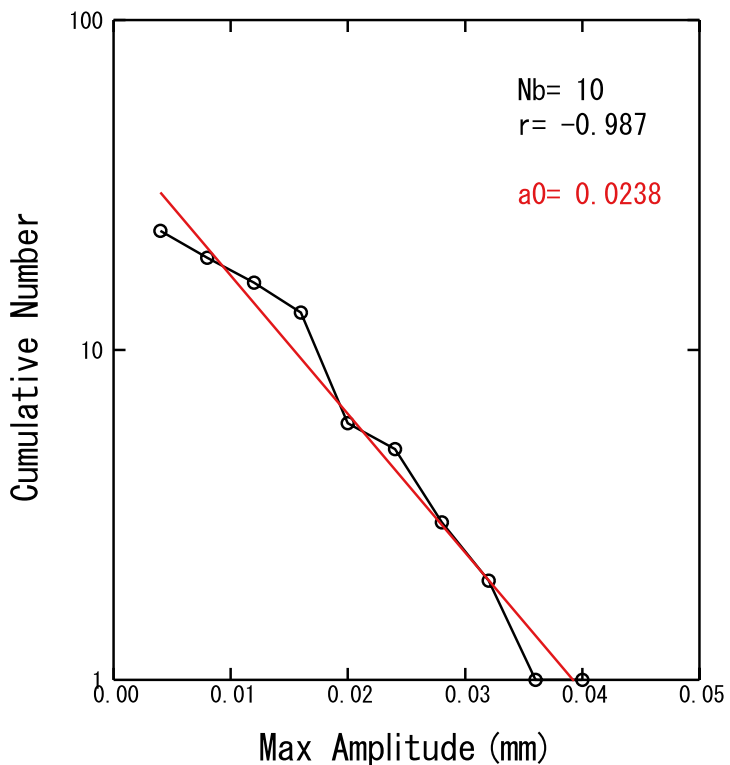

Fig. 3 Magnitude-frequency distributions of explosion earthquakes at a Suwanosejima and $\mathbf{b}$ Tokachi-dake, Japan. Parameter definitions as in Fig. 2

Tokachi-dake volcano exhibited explosive activity from December 1988 to March 1989, and 23 explosive eruptions are listed in Table 1 of Okada et al. (1990) where date and time, amplitude of EXs as well as airwaves are summarized. We use half-amplitudes of EXs that are recorded at JMA-A (TVO) station $4.5 \mathrm{~km}$ NNW from the crater. The number of EXs occurring during this eruptive sequence is small, but we can see in Fig. $3 \mathrm{~b}$ that the exponential distribution seems to explain the observed data well.

\section{Vulcanian eruptions at volcanoes in Indonesia}

Figure $1 \mathrm{~b}$ shows the locations of Semeru and Lokon volcanoes in Indonesia. We analyze seismic data recorded during vulcanian explosive activity in March-April 2007 and gas burst activity in March-April 2009 at Semeru 
(Nishimura et al. 2013). Vulcanian explosions and gas bursts occurred continuously, every few minutes to tens of minutes in 2007 and 2009, respectively. Both kinds of explosions occurred within the same summit crater. Seismic signals were recorded by a broadband seismometer (STS-2, Streckeizen Ltd.) at a station $0.5 \mathrm{~km}$ north of the crater. Hence, most of large seismic events in the continuous records were associated with the repeated crater explosions. We numerically extract EXs based on when the vertical seismic amplitude exceeds a threshold level of $2 \times 10^{-4} \mathrm{~m} / \mathrm{s}$, which is about 10-40 times the ambient noise level. We measure maximum amplitude in the raw broadband seismometer records for each EX. Tectonic earthquakes contamination in the records is eliminated by checking whether or not clear P- and S-waves are observed in the seismograms.

Figure $4 \mathrm{a}, \mathrm{b}$ compares cumulative number of EXs during vulcanian explosions and gas bursts in doublelogarithmic and semilogarithmic graphs. Both doublelogarithmic graphs show convex shapes. On the other hand, the cumulative number plots for both vulcanian eruptions and gas bursts seem to be well fitted by a linear line in the semilogarithmic graphs. This strongly suggests exponential scaling of EXs for vulcanian eruptions and gas bursts at Semeru.

EXs at Lokon are manually selected from continuous records of a broadband seismometer (Trilium40, Nanometrics), installed $1.7 \mathrm{~km}$ from the active crater, for a period of 1 year from September 2012. We measure maximum amplitudes from the raw records. Figure $4 \mathrm{c}$ plots the cumulative number of EXs versus maximum seismic amplitude in double-logarithmic and semilogarithmic graphs. Like the Semeru volcanoes, an exponential distribution explains the observed data at Lokon well.

\section{Strombolian eruptions at Stromboli volcano, Italy}

We deployed one three-component seismometer (Trillium Compact, Nanometrics) at about $400 \mathrm{~m}$ south of the active crater of Stromboli volcano at the end of May 2014 (Fig. 1c). Seismic signals were continuously recorded by a data logger (HKS-9550, Keisokugiken), with a sampling frequency of $100 \mathrm{~Hz}$ and an A/D resolution of 24 bits. We analyze raw seismograms in June 2014, during which strombolian eruptions repeatedly occurred every few minutes to tens of minutes. We numerically extract explosions based on when seismic amplitude exceeds twice the monthly root-mean-square amplitude. As presented in many previous papers (e.g., Neuberg et al. 1994; Ripepe et al. 2001; Chouet et al. 2003), very long-period seismic signals (about $10 \mathrm{~s}$ ) are accompanied by explosions. Since each explosion accompanies very long-period and/or high-frequency (4-7 Hz) seismic waves (Ripepe et al. 2001), we examine maximum peak amplitudes at $0.05-0.2$ and $1-8 \mathrm{~Hz}$. Figure 5 shows the magnitude-frequency distributions. The doublelogarithmic graph at $1-8 \mathrm{~Hz}$ shows a convex shape that looks similar to the distribution presented in Fig. 7 of Del Pezzo et al. (1974). On the other hand, the semilogarithmic graph seems to be approximated by a straight line. The $0.05-0.2 \mathrm{~Hz}$ data also show a similar result. That is, the EX magnitude-frequency distributions at Stromboli are explained by exponential rather than the power-law relationships. It is noted that amplitude ratios of low-frequency $(0.05-0.2 \mathrm{~Hz})$ to high-frequency $(1-8 \mathrm{~Hz})$ wave are not the same for all EXs, although the shape of the magnitude-frequency distribution at $0.05-0.2 \mathrm{~Hz}$ is well matched with that at $1-8 \mathrm{~Hz}$ on the double-logarithmic scale.

It is noteworthy to mention that we only analyze data of standard activity of Stromboli volcano, as no major explosion or paroxysmal activity occurred during our observation period. It is necessary to analyze data over long observations time periods of more than 10 years to encompass the entire eruptive activity types of Stromboli.

\section{Statistical tests on the magnitude-frequency distributions}

So far, we have visually examined EX magnitude-frequency distributions in graphs and indicated that they are best explained by exponential relationships at all of the studied volcanoes, except Suwanosejima. In the present section, we statistically examine the observed magnitude-frequency distributions.

We first analyze correlation coefficients of the EX magnitude-frequency distributions on the double-logarithmic and semilogarithmic graphs (Figs. 2, 3, 4, 5). The correlation coefficients show high values of more than about 0.9 in both types of graph for all of the EXs. This suggests that both relationships explain the observed data well. However, it is clear that correlation coefficients for the semilogarithmic graphs are larger than the double-logarithmic ones for all of EXs except Suwanosejima. All of the semilogarithmic graph coefficients are larger than 0.89 , and most are larger than 0.97 .

We then apply the Kolmogorov-Smirnov test (KS test, hereafter) to the data. The KS test examines the maximum difference, $D_{\max }$, between the observed cumulative probability distribution and the model function. The value $D_{\max } \sqrt{N_{\mathrm{b}}}$, where $N_{\mathrm{b}}$ is the number of bins, is used to examine the hypothesis that the model can explain the observed data. We test two models: exponential distribution and power law. Table 1 shows that $D \max \sqrt{N_{\mathrm{b}}}$ values for EXs at each volcano are smaller than 1.36, which represents the $5 \%$ significance level, for both the power-law and exponential distributions. This means that we cannot statistically reject the two models at the $95 \%$ confidence 


\section{a Semeru Vulcanian 2007}

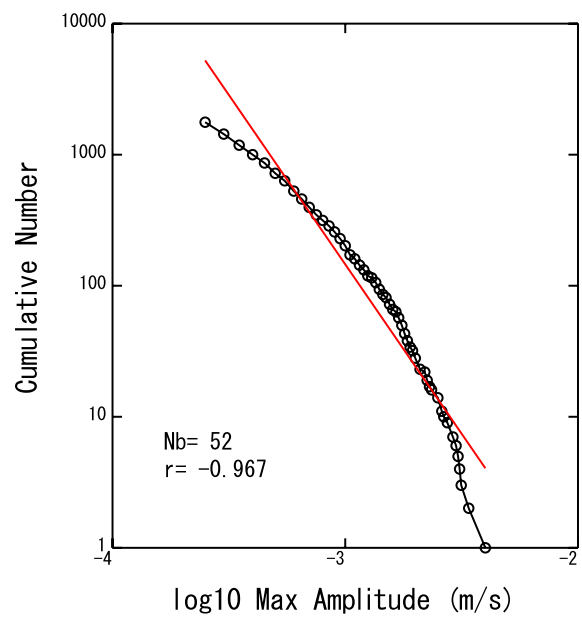

b Semeru Gas Burst 2009

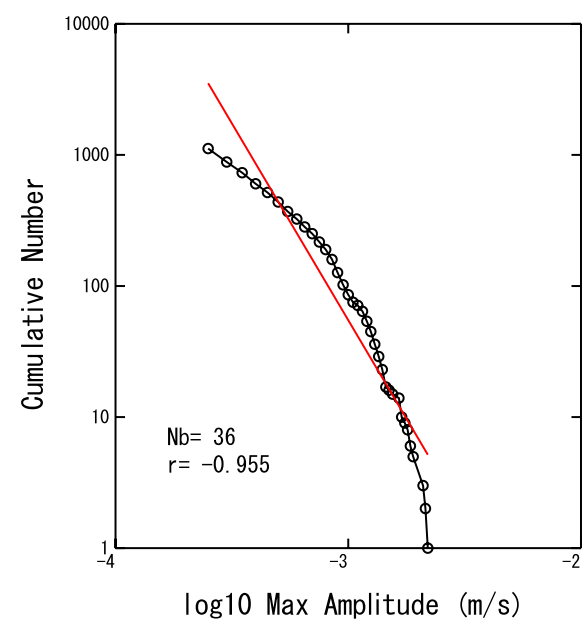

C Lokon

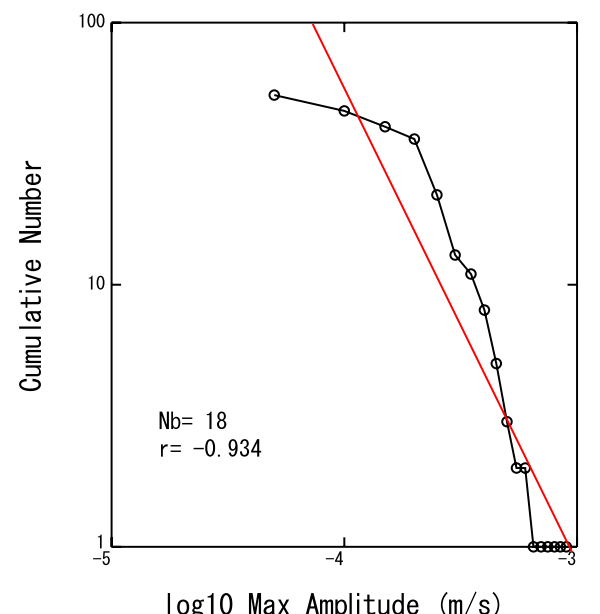

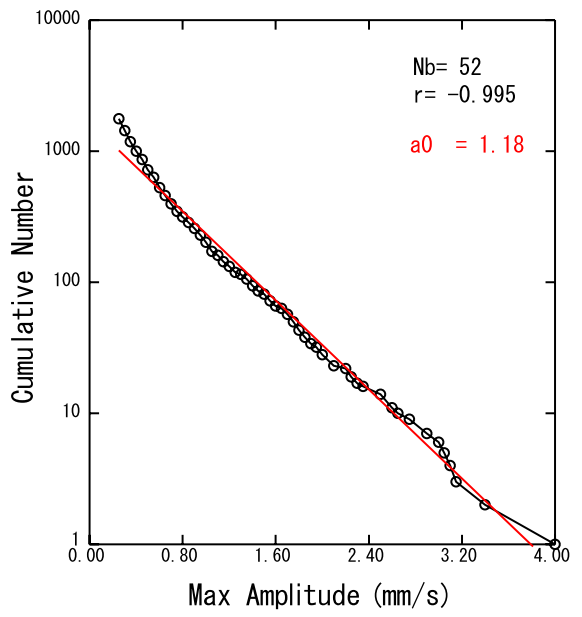
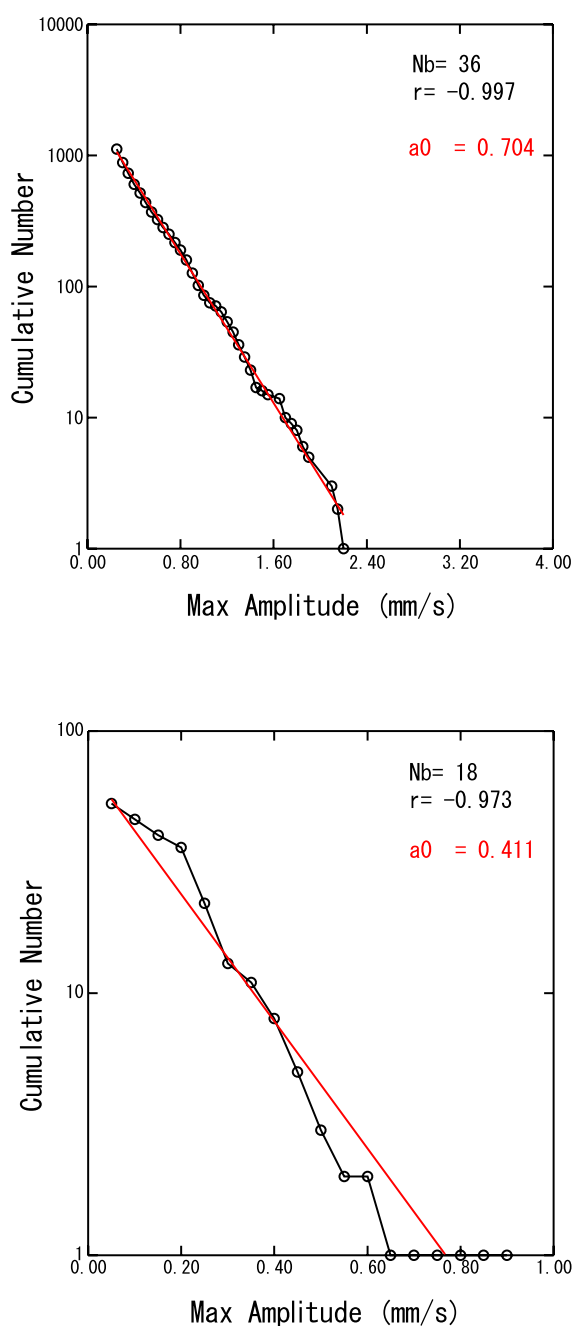

Fig. 4 Magnitude-frequency distribution of explosion earthquakes for a Semaru vulcanian eruptions, b Semeru gas bursts, and $\mathbf{c}$ Lokon volcano, Indonesia. Parameter definitions as in Fig. 2 
level. However, it is recognized that $D_{\max } \sqrt{N_{\mathrm{b}}}$ values for the exponential distributions are smaller than those for the power law for all EXs except Suwanosejima.

Based on these two statistical examinations, we conclude that exponential distributions well match the observed EX magnitude-frequency distributions. This strongly suggests the existence of a characteristic scale in the generation of explosions during each eruptive activity at these volcanoes.

\section{Discussion}

Results shown in the previous sections may be unreliable if low amplitude EXs were not correctly counted due to large noise amplitudes. For example, by removing

a Stromboli June $2014(1-8 \mathrm{~Hz})$
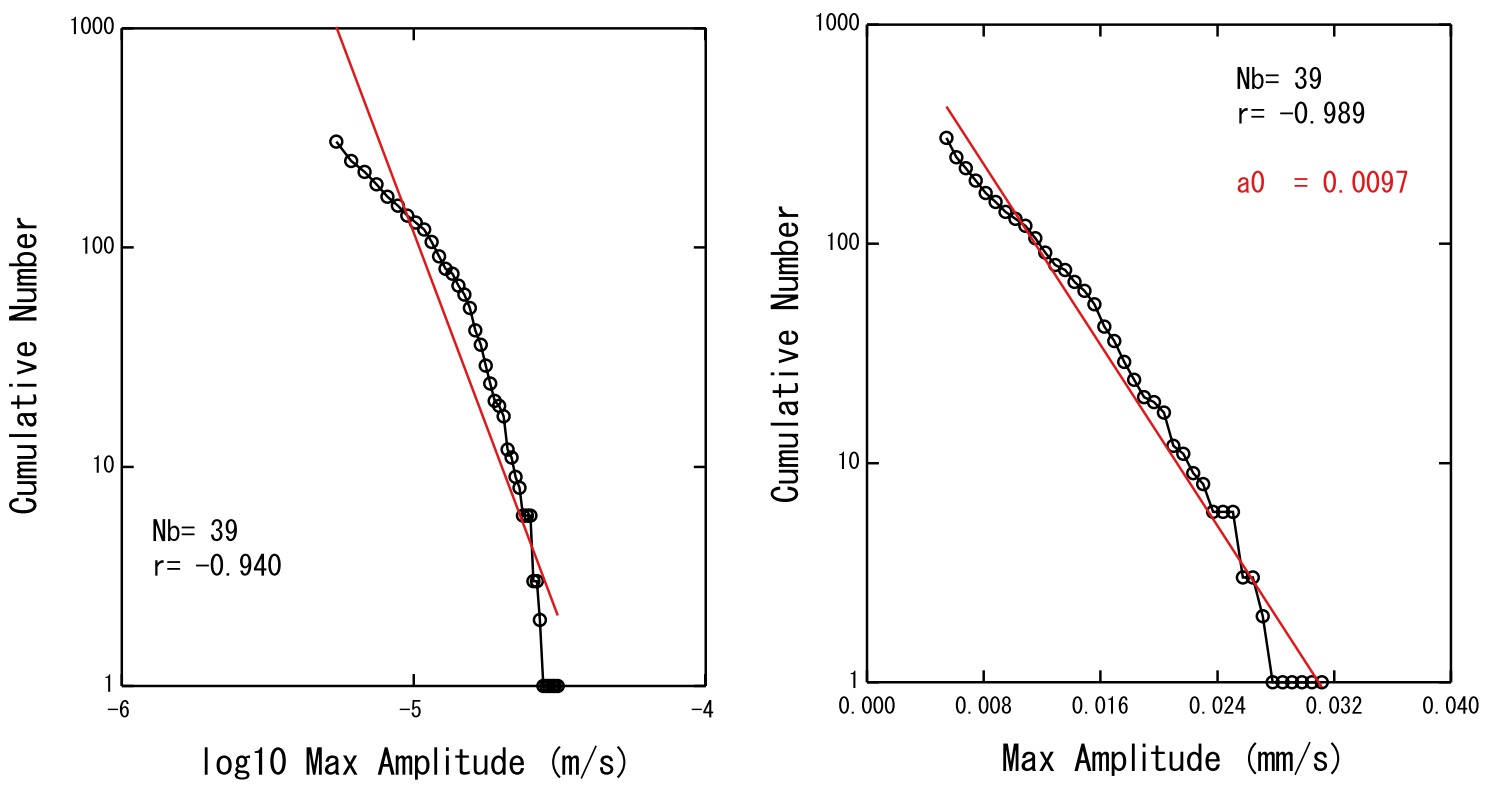

b Stromboli June $2014(0.05-0.2 \mathrm{~Hz})$
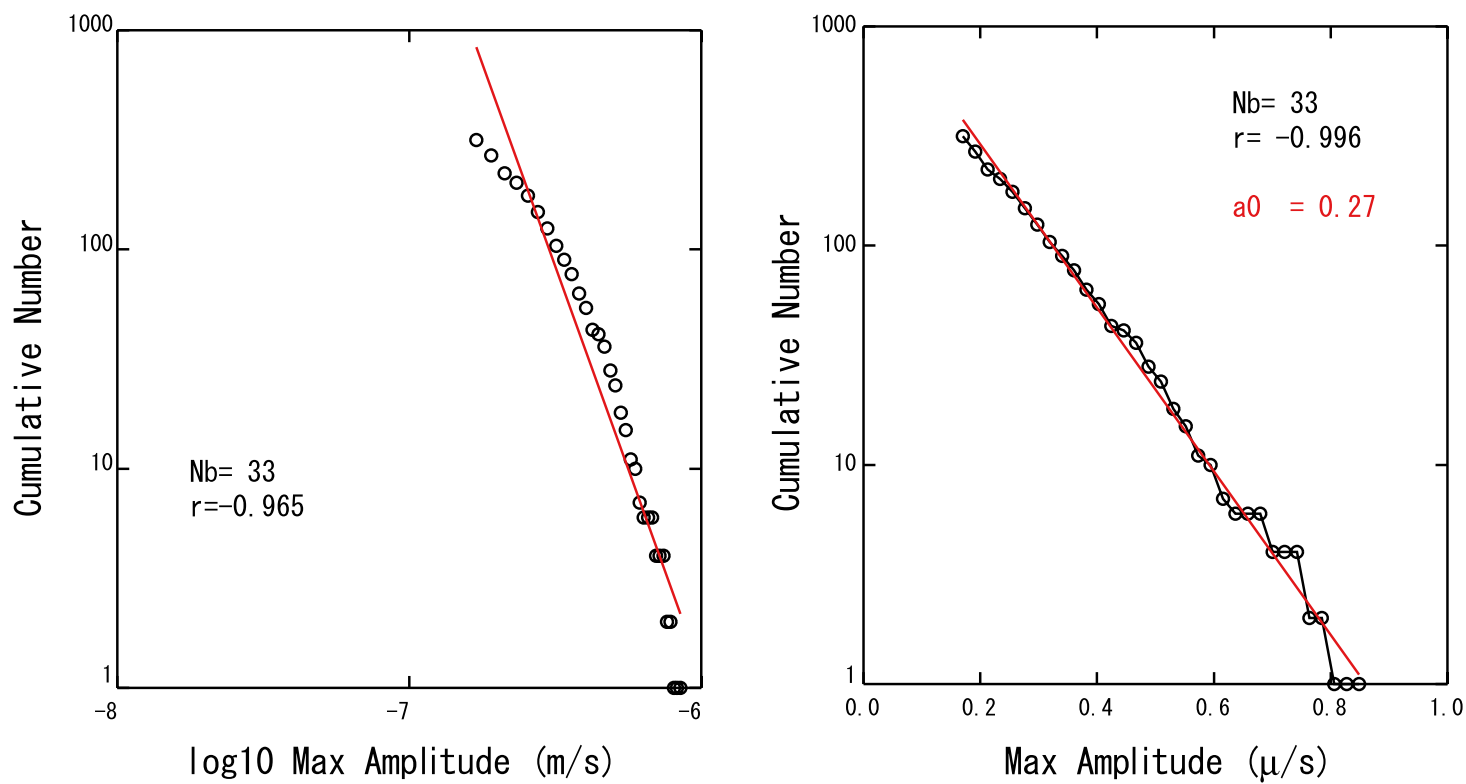

Fig. 5 Magnitude-frequency distribution of explosion earthquakes at Stromboli, Italy. a $1-8 \mathrm{~Hz}$, and $\mathbf{b} 0.05-0.2 \mathrm{~Hz}$. Parameter definitions as in Fig. 2 


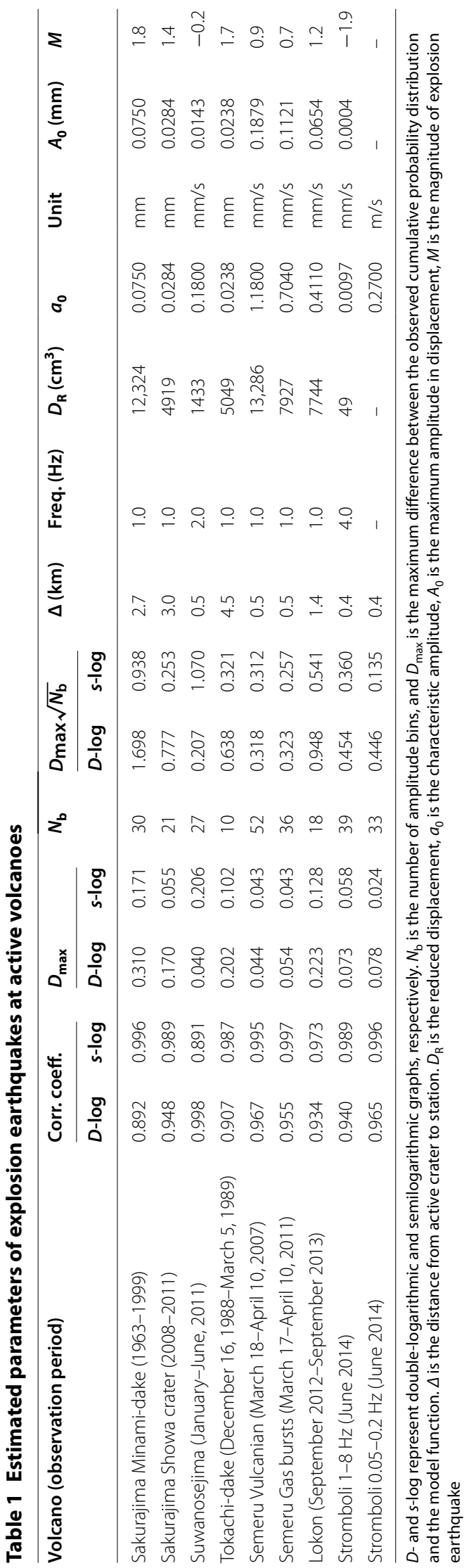


the five lowest-amplitude bins from the Sakurajima EXs plotted on the double-logarithmic scale, correlation coefficients increase from 0.892 to 0974 for 1963-1999 data and from 0.948 to 0.996 for 2008-2011 data. However, EXs are some of the largest earthquakes occurring at Sakurajima and the signal amplitudes are well beyond the noise level. Hence, SVRC correctly detects EXs without interference from noise signals. At Semeru, EXs were selected by setting a high threshold level (10-40 times the noise level), and the magnitude-frequency distributions show a convex shape even in the high amplitude range (see Fig. 4). Similar convex shapes are recognized in full amplitude ranges of Stromboli volcano. These results suggest that low detection levels of EXs in the low amplitude range are not the main cause of the convex shape of the magnitude-frequency distributions, or of the low correlations for the power-law distributions.

We have fitted a straight line on the double-logarithmic scale magnitude-frequency distribution at each volcano. However, as Tanaka et al. (1972) explained in an investigation of data from Akita-Komagatake, Japan, the magnitude-frequency distribution at volcanoes such as Semeru, Stromboli, and Tokachi may be fitted by two straight lines on the double-logarithmic scale. For example, we can see inflections in the magnitude-frequency distribution at about -4.8 on the horizontal axis for Stromboli data, at about -2.8 and -3.1 for Semeru vulcanian and gas burst data, respectively, and -4.7 for Tokachi volcano. Fitting two straight lines to the data implies that the magnitude distribution follows two different power laws; we cannot statistically reject this possibility. Also, we are not able to objectively distinguish it from the exponential distribution, although the power laws are limited in narrow ranges of $<1$ order. If the distributions comprise two power laws, the inflection point may be related to a scale change in the magma system to generate explosions.

EXs are often explained by a single force acting at the shallow part of a volcano (e.g., Kanamori et al. 1984; Ohminato et al. 2006) or by pressure release of a magma chamber (Uhira and Takeo 1994). The amplitude of the single force is proportional to the product of the crosssectional area of the vent and the pressure stored before explosion. The amplitude is related to the time derivative of the seismic moment that is defined by the volume of the chamber. These theoretical predictions indicate that the amplitudes of these sources distribute exponentially. Since EXs at each volcano repeatedly occurred from the same vent or crater, we infer that the characteristic scales are related to the size of conduit or chamber, and fluctuations of excess pressure stored before explosion may change for each explosion.
We have represented the observed exponential distributions by $\log _{10} N=N_{0} \exp \left(-a / a_{0}\right)$, where $N$ is the number of events at the maximum amplitude of $a, N_{0}$ is the constant related to the total number of events. The parameter $a_{0}$ is measured from the slope of the semilogarithmic graphs. To compare the characteristic scales of EXs at different volcanoes, we use the reduced displacement $D_{\mathrm{R}}$ that is an indication of the strength of the seismic source (Aki and Koyanagi 1981), although $D_{\mathrm{R}}$ is generally used to evaluate volcanic tremor sources. EXs generally excite large amplitude Rayleigh waves from a shallow depth in the conduit (Kanamori and Given 1983; Tameguri et al. 2002). Hence, we have assume that the dominant waves are surface waves and determine the reduced displacement, $D_{\mathrm{R}}$, for the surface wave, which is expressed as $D_{\mathrm{R}}=A_{0} \sqrt{\lambda r / 2}$ where $r$ is the epicentral distance, $A_{0}$ the maximum amplitude in displacement, and $\lambda$ the wavelength. We assume a homogenous structure with a surface wave velocity of $1000 \mathrm{~m} / \mathrm{s}$, and the wavelength of the surface waves is calculated from the dominant frequencies $f$. When the observed maximum amplitude is in velocity, we obtain the displacement by using the equation $A_{0}=a_{0} / 2 \pi f$. Table 1 compares the reduced displacements for different EXs. Stromboli data at $0.05-0.2 \mathrm{~Hz}$ are excluded from the analysis, because the long-period waves are near-field and not surface waves. We also evaluate the seismic magnitude $M$ using Tsuboi's formula (Tsuboi 1954), where $M=1.73 \log r+\log A_{0}-0.83$. Seismic magnitudes range from about -0.2 to 2 . From the reduced displacements and seismic magnitudes obtained, the largest EXs are those of vulcanian eruptions at Sakurajima, followed by Tokachi, Semeru, Lokon and Suwanosejima volcanoes. Reduced displacement and seismic magnitude for the 1-8 $\mathrm{Hz}$ Stromboli EXs are much smaller than the others. If the excess pressure before explosion is almost constant, as suggested by Nishimura and Hamaguchi (1993) and Nishimura (1998), which shows a scaling relationship in the amplitude of single force and source duration time, the differences in reduced displacements and seismic magnitudes at these volcanoes may be attributed to vent radius. The differences could be examined in more detail if site amplification factors and attenuation structure, or more detailed waveform analyses using seismic waves, are incorporated in the analyses.

It is well known that the magnitude-frequency distribution of the volcanic explosivity index (VEI, Newhall and Self 1982), which is determined from the volume of ejecta or column height, is expressed by a power law for all volcanoes around the world (Simkin 1993). Recently, Nakada (2015) examined Sakurajima and Izu-Oshima, Japan, and Merapi in Indonesia and indicated that the 

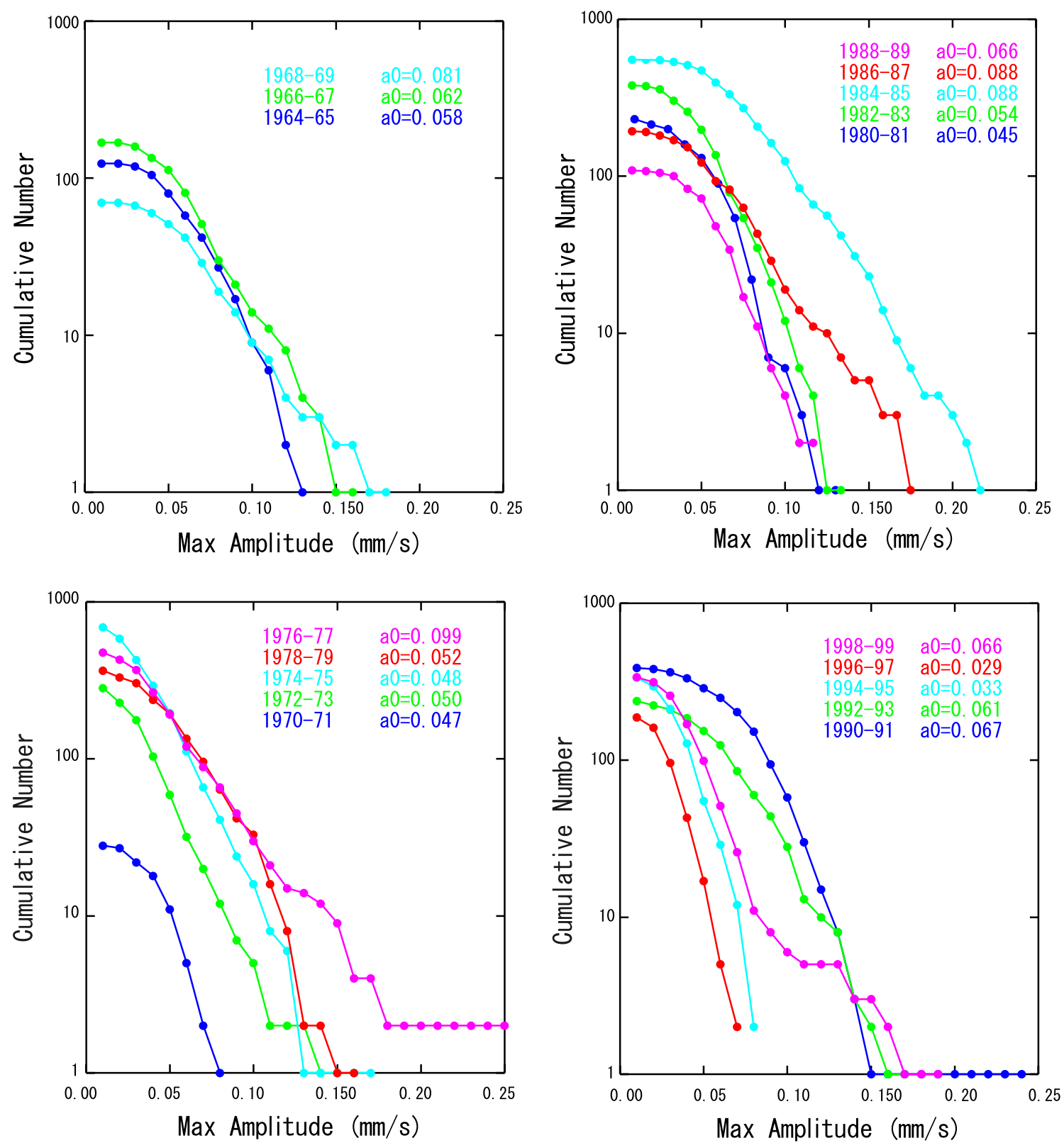

Fig. 6 Magnitude-frequency distributions of explosion earthquakes at Sakurajima, Japan, every 2 years from 1964 to 1999

magnitude-frequency distributions of VEI in the range of 2-6 obey a power law, even for individual volcanoes. Power-law distributions represent self-similar properties in the eruption system and suggest there is no characteristic scale, even in an individual volcano. This is different from the exponential distribution found for EXs and may be attributed to different scaling relations of eruption mechanisms. However, we are not able to discuss the inconsistency in the magnitude-frequency distributions between EXs and VEIs, because the amount of ejecta associated with each EX we analyzed is often too small to evaluate its VEI. Even for large vulcanian eruptions from Minami-dake at Sakurajima, column heights reach about $5000 \mathrm{~m}$ and their VEI is equivalent to 2. The EX magnitude-frequency distributions reflect the statistical characteristics of mechanical properties and may not be directly related to the amount of ejecta that determines the VEI. Further investigation on the volume of ejecta associated with vulcanian eruptions, for example, using ash collectors (e.g., Tajima et al. 2013), is necessary. 
We are not contending that the magnitude-frequency distributions of eruption earthquakes always show exponential or two power-law relationships. Suwanosejima shows a better fit to the power law, and Minakami (1960) indicated that EXs and B-type earthquakes that may be related to small explosions at Sakurajima and Asama volcanoes, Japan, follow the Ishimoto-Iida's formula. It is also noted that our observation periods are limited, and there must be temporal changes in the magnitude-frequency distributions. Figure 6 shows an example of temporal changes in the magnitude-frequency distributions of Sakurajima. Most of the plots show exponential distributions, but the slopes of the graphs change with time: $a_{0}$ values representing the slopes are larger in 1984-1987 than in the other periods, which may reflect changes in eruptive activity and magma system at Sakurajima. We also divide the data at Suwanosejima into two periods, January-February and March-June, but we do not see significant temporal changes in the magnitude-frequency distributions. The origins of temporal changes in the magnitude-frequency distribution at each volcano may be clarified by carefully examining relationships with eruptive activities. It is worthwhile mentioning that the amplitude ranges of most EXs are limited to around one order of magnitude for each volcano. Also, magnitudefrequency distributions may deviate from an exponential form at low and high amplitude ranges, as shown, for example, in the data for amplitudes of $<0.05 \mathrm{~mm} / \mathrm{s}$ at Sakurajima (Fig. 6). These observations need to be considered to understand the overall characteristics of magnitude-frequency distributions of volcanic explosions.

Finally, we discuss the possibility of airwave contamination of EX seismograms. At Sakurajima, maximum amplitudes are measured in the seismograms before the arrival of airwaves. We see ground-coupled airwaves in the seismograms at Semeru and Suwanosejima, but these signals are generally smaller than the maximum amplitude of ground motion. At Lokon, ground-coupled waves are not well recognized, probably because a hill located between the station and crater obstructs the propagation of airwaves. Hence, we simply measured the maximum amplitudes in the EX seismograms for these three volcanoes. There is no detailed description in Okada et al. (1990) on the amplitude measurements at Tokachidake. However, according to Ichihara et al. (2012), the amplitude of ground-coupled airwaves is estimated to be $<$ about $20 \%$ of that of maximum ground motion, based on observation at a nearby station. Hence, the data in Okada et al. (1990) can be reliably used for the examination of EX magnitude-frequency distributions. We analyzed very low-frequency seismic waves $(0.05-0.2 \mathrm{~Hz})$ only for Stromboli, as EXs at the other volcanoes are dominated by short-period waves around $1 \mathrm{~Hz}$, and no significant low-frequency waves are recognized. Also, since impulsive airwaves are generated from vulcanian eruptions, low-pass-filtered seismograms may represent ground-coupled airwaves. Hence, we have not analyzed low-frequency bands for the other volcanoes.

\section{Authors' contributions}

TN carried out seismic data analyses and drafted the manuscript. MI conducted seismic observation at Sakurajima and Suwanosejima volcanoes and analyzed the Sakurajima data. MH designed seismic observations at Semeru and Lokon volcanoes. HA and TY carried out seismic observations at Lokon and Stromboli volcanoes and analyzed the data. MR and RG conducted volcano observations at Stromboli and analyzed the data. All authors read and approved the final manuscript.

\section{Author details}

${ }^{1}$ Department of Geophysics, Graduate School of Science, Tohoku University, 6-3 Aramaki-aza Aoba, Aoba-ku, Sendai 980-8578, Japan. ${ }^{2}$ Sakurajima Volcano Research Center, Disaster Prevention Research Institute, Kyoto University, Kagoshima, Japan. ${ }^{3}$ Centre for Volcanology and Geological Hazard Mitigation, Bandung, Indonesia. ${ }^{4}$ Graduate School of Science, Institute of Seismology and Volcanology, Hokkaido University, Sapporo, Japan. ${ }^{5}$ Dipartimento di Scienze della Terra, Università di Firenze, Firenze, Italy.

\section{Acknowledgements}

We appreciate the careful comments of two anonymous reviewers and the editorial work of Benoit Taisne. This study was partly supported by the Ministry of Education, Culture, Sports, Science and Technology (MEXT) of Japan, under its Observation and Research Program for Prediction of Earthquakes and Volcanic Eruptions, SATREPS project" Multi-disciplinary Hazard Reduction from Earthquakes and Volcanoes in Indonesia" in collaboration with JST, JICA, RISTEK, and LIPI.JST-JICA project, and JSPS bilateral project on Stromboli volcano between Japan and Italy from 2013 to 2015.

Received: 28 March 2016 Accepted: 6 July 2016

Published online: 20 July 2016

\section{References}

Aki K, Koyanagi RY (1981) Deep volcanic tremor and magma ascent mechanism under Kilauea, Hawaii. J Geophys Res 86:7095-7110

Asada T, Suzuki Z, Tomoda Y (1950) On energy and frequency of earthquakes. Bull Seismol Soc Jpn 3:11-15

Benoit JP, McNutt R (2003) Duration-magnitude distribution of volcanic tremor. J Geophys Res. doi:10.1029/2001JB001520

Chouet B, Dawson P, Ohminato T, Martini M, Saccorotti G, Giudicepietro F, De Luca G, Milana G, Scarpa R (2003) Source mechanisms of explosions at Stromboli Volcano, Italy, determined from moment-tensor inversions of very-long-period data. J Geophys Res. doi:10.1029/2002JB001919

Del Pezzo E, Guerra I, Lo Bascio A, Luongo G, Nappi G, Scarpa R (1974) Microtremors and volcanic explosions at Stromboli, part 2. Bull Volcanol 38:1023-1036

Ichihara M, Takeo M, Yokoo A, Oikawa J, Ohminato T (2012) Monitoring volcanic activity using correlation patterns between infrasound and ground motion. Geophys Res Lett. doi:10.1029/2011GL050542

Iguchi M (2013) Magma movement from the deep to shallow Sakurajima volcano as revealed by geophysical observations. Bull Volcanol Soc Jpn 58:1-18

Iguchi M, Yakiwara H, Hendrasto M, Tameguri T, Hirabayashi J (2008) Mechanism of explosive eruption revealed by geophysical observations at the Sakurajima, Suwanosejima and Semeru volcanoes. J Volcanol Geotherm Res 178:1-9

Iguchi M, Tameguri T, Ohta Y, Ueki S, Nakao S (2013) Characteristics of volcanic activity at Sakurajima volcano's Showa crater during the period 2006-2011. Bull Volcanol Soc Jpn 58:115-135

Ishimoto M, lida K (1939) Observations sur les seismes enregistres par le microsismographe construit dernierement (1). Bull Earthq Res Inst Univ Tokyo 17:443-478 (in Japanese with French abstract) 
Kanamori H, Given JW (1983) Lamb pulse observed in nature. Geophys Res Lett 10:373-376

Kanamori H, Given JW, Lay T (1984) Analysis of seismic body waves excited by the Mount St. Helens eruption of May 18, 1980. J Geophys Res 89:1856-1866

McNutt RS, Nishimura T (2008) Volcanic tremor during eruptions: temporal characteristics, scaling and constraints on conduit size and processes. J Volcanol Geotherm Res 178:10-18

Minakami T (1960) Fundamental research for predicting volcanic eruptions. Bull Earth Res Inst 38:497-544

Nakada S (2015) Regularity of volcanic eruptions in terms of volcanic explosivity index (VEI). Bull Volcanol Soc Jpn 60:143-150 (in Japanese with English abstract)

Neuberg J, Luckett R, Ripepe R, Braun T (1994) Highlights from a seismic broadband array on Stromboli volcano. Geophys Res Lett 21:749-752

Newhall CG, Self S (1982) The volcanic explosivity index (VEI): an estimate of explosive magnitude for historical volcanism. J Geophys Res $87: 1231-1238$

Nishimura T (1998) Source mechanisms of volcanic explosion earthquakes: single force and implosive sources. J Volcanol Geotherm Res 86:97-106

Nishimura T, Hamaguchi H (1993) Scaling law of volcanic explosion earthquake. Geophys Res Lett 20:2479-2482

Nishimura T, Iguchi M, Yakiwara H, Oikawa J, Kawaguchi R, Aoyama H, Nakamichi H, Ohta Y, Tameguri T (2013) Mechanism of small vulcanian eruptions at Suwanosejima volcano, Japan, as inferred from precursor inflations and tremor signals. Bull Volcanol 75:779. doi:10.1007/s00445-013-0779-1

Ohminato T, Takeo M, Kumagai H, Yamashina T, Oikawa J, Koyama E, Tsuji H, Urabe T (2006) Vulcanian eruptions with dominant single force components observed during the Asama 2004 volcanic activity in Japan. Earth Planets Space 58:583-593

Okada H, Nishimura Y, Miyamachi H, Mori H, Ishihara K (1990) Geophysical significance of the 1988-1989 explosive eruptions of Mt. Tokachi, Hokkaido, Japan. Bull Volcanol Soc Jpn 35:175-203
Ripepe M, Ciliberto S, Schiava MD (2001) Time constraints for modeling source dynamics of volcanic eruptions at Stromboli. J Geophys Res 106:8713-8727

Rowe CA, Aster RC, Kyle PR, Dibble RR, Schlue JW (2000) Seismic and acoustic observations at Mount Erebus volcano, Ross island, Antarctica, 1994-1998. J Volcanol Geotherm Res 101:105-128

Shimozuru D, Gyoda N, Takeda T (1971) Seismic observation of the eruption of Akita-Komaga-take. Bull Volcanol Soc Jpn 16:143-152 (in Japanese with English abstract)

Simkin T (1993) Terrestrial volcanism in space and time. Annu Rev Earth Planet Sci 21:427-452

Suzuki Z (1953) A study on the occurrence of small earthquakes I. Sci Rep Tohoku Univ Ser 5 Geophys 5:177-182

Tajima Y, Tamura K, Yamakoshi T, Tsune A, Tsurumoto S (2013) Ellipse-approximated isopach maps for estimating ash fall volume at Sakurajima volcano. Bull Volcanol Soc Jpn 58:291-306

Tameguri T, Iguchi M, Ishihara K (2002) Mechanism of explosive eruptions from moment tensor analyses of explosion earthquakes at Sakurajima volcano, Japan. Bull Volcanol Soc Jpn 47:197-215

Tanaka Y (1967) On the explosion-earthquake at the Volcano Sakurajima. Bull Volcanol Soc Jpn 12:26-40 (in Japanese with English abstract)

Tanaka K, Kasahara M, Hori S, Suzuki Z, Takagi A (1972) Research on AkitaKomaga-take (I)—summary of its eruptions in 1970-1971. Sci Rep Tohoku Univ Ser 5 Geophys 21:61-75

Tsuboi T (1954) Determination of the Gutenberg-Richter's magnitude of earthquakes occurring in and near Japan. Bull Seismol Soc Jpn 7:185-193 (in Japanese with English abstract)

Uhira K, Takeo M (1994) The source of explosive eruptions of Sakurajima volcano, Japan. J Geophys Res 99:17775-17789

\section{Submit your manuscript to a SpringerOpen ${ }^{\odot}$ journal and benefit from:}

- Convenient online submission

- Rigorous peer review

Immediate publication on acceptance

- Open access: articles freely available online

- High visibility within the field

- Retaining the copyright to your article

Submit your next manuscript at springeropen.com 